\title{
Acyclovir-Induced Nephrotoxicity: The Protective Benefit of Curcumin
}

\author{
Elias Adikwu' ${ }^{1}$, James Kemelayefa ${ }^{1}$ \\ 'Niger Delta University, Faculty of Pharmacy, Department of Pharmacology and Toxicology, Bayelsa State, Nigeria
}

ORCID IDs of the authors: E.A. 0000-0003-4349-8227; J.K. 0000-0003-2713-9945

Please cite this article as: Adikwu E, Kemelayefa J. Acyclovir-Induced Nephrotoxicity: The Protective Benefit of Curcumin. Eur J Biol 2021; 80(1): 22-28. DOI: 10.26650/EurJBiol.2021.903407

\begin{abstract}
Objective: Nephrotoxicity may decrease the clinical use of acyclovir (ACV). Curcumin (CUM) is used traditionally as treatments for some diseases. This study examined the protective effect of CUM against ACV-induced nephrotoxicity in rats.

Materials and Methods: Forty-five male Wistar rats (240-250g) randomized into nine groups ( $n=5)$ were used. Group 1 (Placebo control) received water $(0.2 \mathrm{~mL} /$ day) intraperitoneally (i.p) whereas group 2 (Solvent control) received corn oil $(0.2 \mathrm{~mL} /$ day) per oral (p.o) for 7 days. Groups 3-5 received CUM ( 25,50 and $100 \mathrm{mg} / \mathrm{kg} /$ day p.o) for 7 days. Group 6 received ACV ( $150 \mathrm{mg} / \mathrm{kg} /$ day i.p) for 7 days. Groups 7-9 were pre-treated with CUM (25, 50 and $100 \mathrm{mg} / \mathrm{kg} /$ day p.o) before the treatment with ACV ( $150 \mathrm{mg} / \mathrm{kg} /$ day i.p) for 7 days. On day 8 , the rats were anesthetized; blood samples were collected and evaluated for serum biochemical indices. The $k$ idneys were weighed and assessed for histology and oxidative stress indices.

Results: ACV produced no significant ( $p>0.05$ ) effects on the body and kidney weights of rats when compared to control. ACV caused significant $(p<0.001)$ elevations in serum creatinine, urea, uric acid and kidney malondialdehyde levels when compared to control. ACV significantly $(p<0.001)$ decreased kidney glutathione,catalase, glutathione peroxidase, superoxide dismutase, serum total protein, albumin, potassium, chloride, sodium and bicarbonate levels when compared to control. Tubular necrosis and hypercellular glomerulus with mesangial proliferation occurred in the ACV-treated rats. ACV-induced nephrotoxicity was abrogated in a dose-related fashion by CUM $25 \mathrm{mg} / \mathrm{kg}(p<0.05), 50 \mathrm{mg} / \mathrm{kg}(\mathrm{p}<0.01)$ and $100 \mathrm{mg} / \mathrm{kg}$ $(p<0.001)$ when compared to ACV.
\end{abstract}

Conclusion: CUM may clinically prevent ACV-induced nephrotoxicity.

Keywords: Acyclovir, Curcumin, Kidney, Toxicity, Protection, Rat

\section{INTRODUCTION}

The kidney regulates body homeostasis through its excretory functions and important metabolic activities in the tubular epithelial cells. It is involved in the syntheses of hormones, and the degradation of low-molecular-weight proteins and peptides (1). The kidney is a major route of drug excretion, which predisposes it to nephrotoxicity. Drug-induced nephrotoxicity is an important cause of acute and chronic renal failure (2). Drugs have been responsible for $19 \%-25 \%$ of acute renal failure in patients admitted in hospitals $(3,4)$.
Acyclovir (ACV), an antiviral drug, is used for the treatment of varicella-zoster and herpes simplex virus infections $(5,6)$. It is well tolerated, but can cause nephrotoxicity, which often leads to acute renal failure $(7,8)$. Epidemiology showed it may cause nephrotoxicity in $12 \%$ to $48 \%$ of patients $(6,9)$. The nephrotoxic effect of $\mathrm{ACV}$ is primarily characterized by elevated plasma urea and creatinine levels and abnormal urine sediments (10, 11). It can also be characterized by degenerative alterations in tubular epithelial cells such as tubular necrosis $(10,11)$. The mechanisms by which ACV causes nephrotoxicity have been speculated to involve direct assault on renal tubular cells and oxidative stress $(11,12)$. 
Curcumin (CUM) (1,7-bis(4-hydroxy-3-methoxyphenyl)-1,6-heptadiene-3,5-dione) also known as diferuloylmethane is a natural yellow orange dye derived from the rhizome of Curcuma longa Linn., belonging to Zingiberaceae family $(13,14)$. CUM is a polyphenol, which has been shown to target multiple signaling molecules. It has activity at the cellular level with multiple health benefits (15). It is locally used as treatments for inflammation, metabolic syndrome, microbial infections, pain, and degenerative eye conditions (16-18). Potential effect of CUM as an antidote against toxicities, such as hepatotoxicity (19) nephrotoxicity (19) and cardiotoxicity (20) in animal models has been documented. Scientific information showed no study on the protective effect of CUM against animal models of ACV-induced nephrotoxicity, thus this study examined its protective effect against a rat model of ACV-induced nephrotoxicity.

\section{MATERIALS AND METHODS}

The guideline for the use of animals in experiments promulgated by the European Parliament and the Council was used for this study. Forty-five adult male Wistar rats were purchased from the animal breeding facility of the Department of Pharmacology/Toxicology, Faculty of Pharmacy, Niger Delta University, Bayelsa State, Nigeria. The rats were randomized into 9 groups of $n=5$ and allowed to acclimatize for 2 weeks prior to the experiment under 12/12-hour light and dark cycles with ad libitum access to diet and water. The study was approved by the Research Ethics Committee (NDU/PHARM/AEC/046) of the Department of Pharmacology/Toxicology, Faculty of Pharmacy, Niger Delta University, Bayelsa State Nigeria.

\section{Animal Treatment}

Group I (Placebo control) was treated with water $(0.2 \mathrm{~mL})$ intraperitoneally (i.p) daily for 7 days. Group 2 (Solvent control) was treated with corn oil $(0.2 \mathrm{~mL})$ per oral (p.o) daily for 7 days. Groups 3-5 were treated with $\operatorname{CUM}(25,50$ and $100 \mathrm{mg} / \mathrm{kg} / \mathrm{p.o})$ in corn oil (21) daily for 7 days. Group 6 was treated with ACV (150 mg/kg/i.p) (22) daily for 7 days. Groups 7-9 were supplemented with CUM $(25,50$ and $100 \mathrm{mg} / \mathrm{kg} / \mathrm{p} . \mathrm{o})$ prior to the treatment with ACV (150 mg/kg/i.p) for 7 days. Peperine $(20 \mathrm{mg} / \mathrm{kg})$ was added to CUM to improve bioavailability (21).

\section{Animal Sacrifice and Collection of Samples}

On day 8 , the rats were anesthetized in a diethyl ether chamber and blood samples were collected through cardiac puncture and allowed to clot. The clots were centrifuged (1500 rmp for $20 \mathrm{~min}$ ) and serum samples were extracted. The serum samples were used for biochemical investigations. The kidneys were collected through dissection, rinsed in physiological saline and homogenized in buffered ( $\mathrm{pH}$ 7.4) $0.1 \mathrm{M}$ Tris- $\mathrm{HCl}$ solution. The homogenates were centrifuged (2000 rmp for $20 \mathrm{~min}$ ), and the supernatants were decanted and used for oxidative stress markers investigations.

\section{Assessment of Serum Biochemical Markers}

Serum total protein, albumin, creatinine, uric acid, urea, sodium, potassium, chloride and bicarbonate concentrations were measured using laboratory test kits according manufacturer's specification.

\section{Assessment of Kidney Oxidative Stress Markers}

Malondialdehyde (MDA) was measured according to the method reported by Buege and Aust, 1978 (23). Catalase (CAT) was measured as described by Aebi, 1984 (24). Superoxide dismutase (SOD) was analyzed as described by Sun and Zigman, 1978 (25). Glutathione (GSH) was determined using the method described by Sedlak and Lindsay, 1968 (26). Glutathione peroxidase (GPx) was determined as reported by Rotrucket al. 1973 (27).

\section{Statistical Analysis}

Values are expressed as mean $\pm S E M, n=5$. Values were analyzed using one-way analysis of variance (ANOVA) followed by Dunnett's multiple comparison tests. Graph Pad prism 5 (San Diego, CA) soft ware was used for computation. A probability value less than 0.05 . 0.01, 0.001 was considered significant.

\section{RESULTS}

\section{Effect of Curcumin on Body and Kidney Weights of Acyclovir- Treated Rats}

The rats treated with CUM showed $(p>0.05)$ no difference in body and kidney weights when compared to control. Also, body and kidney weights were not different in the ACV-treated rats ( $p>0.05)$ when compared to control (Table 1$)$.

Table 1. Effects of curcumin on body and kidney weights of acyclovir-treated rats.

\begin{tabular}{lccc}
\hline Group & Final body weight $(\mathbf{g}) *$ & Absolute kidney weight (g)* $^{*}$ & Relative kidney weight (\%)* \\
\hline Control (Placebo) & $240.8 \pm 13.5$ & $0.65 \pm 0.07$ & $0.27 \pm 0.06$ \\
\hline Control(Solvent) & $245.0 \pm 15.9$ & $0.67 \pm 0.01$ & $0.28 \pm 0.01$ \\
\hline CUM $25 \mathrm{mg} / \mathrm{kg}$ & $250.1 \pm 16.0$ & $0.60 \pm 0.03$ & $0.24 \pm 0.01$ \\
\hline CUM $50 \mathrm{mg} / \mathrm{kg}$ & $245.7 \pm 14.1$ & $0.66 \pm 0.01$ & $0.27 \pm 0.07$ \\
\hline CUM $100 \mathrm{mg} / \mathrm{kg}$ & $257.3 \pm 16.4$ & $0.61 \pm 0.04$ & $0.24 \pm 0.05$ \\
\hline ACV $150 \mathrm{mg} / \mathrm{kg}$ & $240.8 \pm 17.2$ & $0.67 \pm 0.06$ & $0.29 \pm 0.01$ \\
\hline CUM $25 \mathrm{mg} / \mathrm{kg}+\mathrm{ACV}$ & $245.4 \pm 14.0$ & $0.63 \pm 0.07$ & $0.26 \pm 0.03$ \\
\hline CUM $50 \mathrm{mg} / \mathrm{kg}+\mathrm{ACV}$ & $244.7 \pm 18.2$ & $0.60 \pm 0.08$ & $0.25 \pm 0.06$ \\
\hline CUM $100 \mathrm{mg} / \mathrm{kg}+\mathrm{ACV}$ & $245.0 \pm 16.6$ & $0.59 \pm 0.05$ & $0.24 \pm 0.02$ \\
\hline *Values are shown as mean \pm SEM; $\mathrm{n}=5 ;$ CUM: Curcumin; ACV: Acyclovir; SEM: Standard error of mean. & \\
\hline
\end{tabular}




\section{Effect of Curcumin on Serum Biochemical Markers of Acyclovir-Treated Rats}

Treatment with CUM did not produce significant ( $p>0.05)$ effects on serum total protein, albumin, uric acid, creatinine and urea levels in comparison to control. In contrast, serum uric acid, creatinine and urea levels were significantly $(p<0.001)$ increased whereas total protein and albumin levels were significantly $(p<0.001)$ decreased in the ACV-treated rats when compared to control (Table 2). However, CUM (25, 50 and $100 \mathrm{mg} / \mathrm{kg}$ ) supplementation significantly decreased serum uric acid, creatinine and urea levels, but significantly increased serum albumin and total protein levels in a dose-related fashion at $p<0.05, p<0.01$ and $p<0.001$, respectively when compared to ACV (Table 2 ).

\section{Effect of Curcumin on Serum Electrolytes of Acyclovir- Treated Rats}

Treatment with CUM had no significant ( $p>0.05$ ) effects on serum electrolytes in comparison to control. However, significant decreases in serum electrolytes were observed in the ACV -treated rats when compared to control (Table 3). Interestingly, CUM (25, 50 and $100 \mathrm{mg} / \mathrm{kg}$ ) supplementation significantly increased serum electrolytes at $p<0.05, p<0.01$ and $p<0.01$, respectively when compared to ACV (Table 3 ).

\section{Effect of Curcumin on Kidney Oxidative Stress Markers of Acyclovir-Treated Rats}

Treatment with CUM did not produce significant $(p>0.05)$ effects on kidney MDA and antioxidant (GPx, SOD, GSH, and CAT)

Table 2. Effect of curcumin on serum biochemical markers of acyclovir-treated rats.

\begin{tabular}{|c|c|c|c|c|c|}
\hline Group & Urea $(\mathrm{mg} / \mathrm{dL}) *$ & Creatinine $(\mathrm{mg} / \mathrm{dL}) *$ & Uric Acid (mg/dL)* & Total Protein $(\mathrm{g} / \mathrm{dL}) *$ & Albumin (g/dL)* \\
\hline Control (Placebo) & $14.84 \pm 1.32$ & $0.67 \pm 0.45$ & $1.41 \pm 0.06$ & $4.00 \pm 0.52$ & $3.09 \pm 0.22$ \\
\hline Control (Solvent) & $14.06 \pm 1.00$ & $0.69 \pm 0.11$ & $1.53 \pm 0.09$ & $4.11 \pm 0.62$ & $3.13 \pm 0.70$ \\
\hline CUM 25 mg/kg & $14.62 \pm 1.54$ & $0.65 \pm 0.08$ & $1.39 \pm 0.07$ & $4.02 \pm 0.78$ & $3.11 \pm 0.45$ \\
\hline CUM 50 mg/kg & $14.76 \pm 1.00$ & $0.66 \pm 0.06$ & $1.37 \pm 0.01$ & $4.04 \pm 0.61$ & $3.14 \pm 0.64$ \\
\hline CUM 100 mg/kg & $14.48 \pm 1.24$ & $0.63 \pm 0.01$ & $1.35 \pm 0.16$ & $4.07 \pm 0.17$ & $3.16 \pm 0.73$ \\
\hline ACV 150 mg/kg & $38.91 \pm 4.51^{\mathrm{a}}$ & $2.59 \pm 0.44^{\mathrm{a}}$ & $4.30 \pm 0.75^{a}$ & $1.30 \pm 0.61^{\mathrm{a}}$ & $1.01 \pm 0.07^{a}$ \\
\hline CUM 25 mg/kg+ACV & $29.64 \pm 3.21^{b}$ & $2.00 \pm 0.36^{b}$ & $3.10 \pm 0.67^{b}$ & $2.10 \pm 0.56^{b}$ & $1.40 \pm 0.09^{b}$ \\
\hline CUM $50 \mathrm{mg} / \mathrm{kg}+\mathrm{ACV}$ & $21.34 \pm 2.78^{c}$ & $1.32 \pm 0.10^{c}$ & $2.37 \pm 0.91^{c}$ & $2.87 \pm 0.69^{c}$ & $2.01 \pm 0.27^{c}$ \\
\hline CUM $100 \mathrm{mg} / \mathrm{kg}+\mathrm{ACV}$ & $16.16 \pm 1.48^{d}$ & $0.80 \pm 0.06^{d}$ & $1.63 \pm 0.55^{d}$ & $3.88 \pm 0.75^{d}$ & $2.87 \pm 0.86^{d}$ \\
\hline
\end{tabular}

*Values are shown as mean \pm SEM. $n=5$; CUM: Curcumin; ACV: Acyclovir; SEM: Standard error of mean. ${ }^{a} p<0.001$ when compared to control. ${ }^{b} p<0.05$ when compared to $A C V, c p<0.01$ when compared to $A C V,{ }^{d} p<0.001$ when compared to $A C V$.

Table 3. Effect of curcumin on serum electrolytes of acyclovir-treated rats.

\begin{tabular}{lcccc}
\hline Group & Potassium (mmo/L)* & Chloride (mmo/L)* & Sodium (mmo/L)* & Bicarbonate (mmo/L)* \\
\hline Control (Placebo) & $3.63 \pm 0.19$ & $112.93 \pm 13.8$ & $147.83 \pm 14.3$ & $10.65 \pm 1.66$ \\
\hline Control (Solvent) & $3.71 \pm 0.23$ & $117.02 \pm 10.1$ & $149.27 \pm 16.7$ & $10.91 \pm 1.91$ \\
\hline CUM $25 \mathrm{mg} / \mathrm{kg}$ & $3.62 \pm 0.04$ & $111.60 \pm 13.0$ & $146.24 \pm 16.0$ & $10.26 \pm 1.46$ \\
\hline CUM $50 \mathrm{mg} / \mathrm{kg}$ & $3.60 \pm 0.30$ & $110.05 \pm 10.4$ & $149.05 \pm 13.8$ & $11.03 \pm 2.49$ \\
\hline CUM $100 \mathrm{mg} / \mathrm{kg}$ & $3.58 \pm 0.06$ & $109.84 \pm 15.2$ & $145.91 \pm 17.1$ & $10.31 \pm 1.01$ \\
\hline ACV $150 \mathrm{mg} / \mathrm{kg}$ & $2.40 \pm 0.17^{\mathrm{a}}$ & $58.73 \pm 5.33^{\mathrm{a}}$ & $78.50 \pm 5.64^{\mathrm{a}}$ & $4.10 \pm 0.27^{\mathrm{a}}$ \\
\hline CUM $25 \mathrm{mg} / \mathrm{kg}+\mathrm{ACV}$ & $3.10 \pm 0.06^{\mathrm{b}}$ & $79.92 \pm 4.17^{\mathrm{b}}$ & $99.14 \pm 7.16^{\mathrm{b}}$ & $6.00 \pm 0.07^{\mathrm{b}}$ \\
\hline CUM $50 \mathrm{mg} / \mathrm{kg}+\mathrm{ACV}$ & $3.51 \pm 0.43^{\mathrm{c}}$ & $99.26 \pm 8.33^{\mathrm{c}}$ & $139.87 \pm 9.66^{\mathrm{c}}$ & $8.70 \pm 1.01^{\mathrm{c}}$ \\
\hline CUM $100 \mathrm{mg} / \mathrm{kg}+\mathrm{ACV}$ & $3.60 \pm 0.36^{\mathrm{c}}$ & $100.03 \pm 11.5^{\mathrm{c}}$ & $140.03 \pm 12.1^{\mathrm{c}}$ & $10.24 \pm 1.12^{\mathrm{c}}$ \\
\hline
\end{tabular}

*Values are shown as mean \pm SEM. $n=5$; CUM: Curcumin; ACV: Acyclovir; SEM: Standard error of mean. ${ }^{\mathrm{a}} \mathrm{p}<0.01$ when compared to control. ${ }^{\mathrm{b}} \mathrm{p}<0.05$ when compared to $A C V, c p<0.01$. 
Table 4. Effect of curcumin on kidney oxidative stress and antioxidant markers of acyclovir-treated rats.

\begin{tabular}{|c|c|c|c|c|c|}
\hline Group & $\begin{array}{c}\text { MDA } \\
\text { (mmol/mg protein)* }\end{array}$ & $\begin{array}{c}\text { GSH } \\
(\mu \mathrm{mole} / \mathrm{mg} \text { protein })^{*}\end{array}$ & $\begin{array}{c}\text { CAT } \\
\text { (U/mg protein)* }\end{array}$ & $\begin{array}{c}\text { SOD } \\
\text { (U/mg protein)* }\end{array}$ & $\begin{array}{c}\text { GPx } \\
\text { (U/mg protein)* }\end{array}$ \\
\hline Control (Placebo) & $0.17 \pm 0.08$ & $20.01 \pm 2.47$ & $29.76 \pm 4.67$ & $25.46 \pm 3.54$ & $25.07 \pm 4.71$ \\
\hline Control (Solvent) & $0.18 \pm 0.01$ & $20.53 \pm 1.67$ & $29.93 \pm 3.88$ & $26.03 \pm 2.37$ & $25.35 \pm 3.35$ \\
\hline CUM 25 mg/kg & $0.16 \pm 0.05$ & $20.47 \pm 2.55$ & $30.07 \pm 4.21$ & $25.61 \pm 3.75$ & $25.16 \pm 3.03$ \\
\hline CUM $50 \mathrm{mg} / \mathrm{kg}$ & $0.16 \pm 0.01$ & $20.70 \pm 3.86$ & $30.25 \pm 3.72$ & $25.72 \pm 3.32$ & $25.36 \pm 4.22$ \\
\hline CUM $100 \mathrm{mg} / \mathrm{kg}$ & $0.15 \pm 0.08$ & $21.04 \pm 2.73$ & $30.44 \pm 4.21$ & $25.91 \pm 3.68$ & $25.52 \pm 3.51$ \\
\hline ACV $150 \mathrm{mg} / \mathrm{kg}$ & $3.12 \pm 0.16^{a}$ & $5.51 \pm 0.45^{\mathrm{a}}$ & $8.11 \pm 1.27^{a}$ & $7.32 \pm 0.11^{\mathrm{a}}$ & $8.065 \pm 0.93^{a}$ \\
\hline CUM $25 \mathrm{mg} / \mathrm{kg}+\mathrm{ACV}$ & $2.59 \pm 0.23^{b}$ & $8.84 \pm 0.86^{b}$ & $12.76 \pm 0.43^{b}$ & $11.74 \pm 3.17^{b}$ & $12.14 \pm 1.43^{b}$ \\
\hline CUM $50 \mathrm{mg} / \mathrm{kg}+\mathrm{ACV}$ & $2.00 \pm 0.44^{c}$ & $12.93 \pm 2.55^{c}$ & $18.35 \pm 1.07^{c}$ & $17.40 \pm 3.00^{c}$ & $17.56 \pm 2.25^{c}$ \\
\hline CUM $100 \mathrm{mg} / \mathrm{kg}+\mathrm{ACV}$ & $0.23 \pm 0.09^{d}$ & $18.45 \pm 2.42^{\mathrm{d}}$ & $26.27 \pm 3.24^{d}$ & $23.75 \pm 3.63^{d}$ & $22.15 \pm 2.11^{d}$ \\
\hline \multicolumn{6}{|c|}{$\begin{array}{l}\text { *Values are shown as mean } \pm \text { SEM. } n=5 \text {; SEM: Standard error of mean; CUM: Curcumin; ACV: Acyclovir; MDA: Malondialdehyde; GSH: Glutathione; CAT: Catalase; } \\
\text { SOD: Superoxide dismutase; GPx: Glutathione peroxidase; }{ }^{a} p<0.001 \text { when compared to control. }{ }^{b} p<0.05 \text { when compared to } A C V \text {, } c p<0.01 \text { when compared to } A C V \text {, } \\
{ }^{d} p<0.001 \text { when compared to ACV. }\end{array}$} \\
\hline
\end{tabular}

levels when compared to control. On the other hand, treatment with ACV significantly $(p<0.001)$ increased kidney MDA level, but significantly $(p<0.001)$ decreased kidney antioxidant levels when compared to control (Table 4). However, significant increases in kidney antioxidants with significant decreases in kidney MDA levels were observed in $\operatorname{CUM}(25,50$ and $100 \mathrm{mg} / \mathrm{kg})$ supplemented rats in a dose-related fashion at $p<0.05, p<0.01$ and $p<0.001$, respectively when compared to ACV (Table 4).

\section{Effect of Curcumin on Kidney Histology of Acyclovir-Treated Rats}

The kidney of the control rat showed normal glomerulus and renal tubule (Figure $1 \mathrm{~A}$ ), but the kidney of ACV-treated rat showed hypercellular glomerulus with mesangial proliferation and tubular necrosis (Figure 1B). The kidney of CUM (25 mg/kg and $50 \mathrm{mg} / \mathrm{kg}$ ) supplemented rats showed hypercellular glomeruli with mesangial proliferation and normal renal tubules (Figures $1 \mathrm{C}$ and D) respectively. However, the kidney of CUM (100 mg/kg) supplemented rat showed normal glomerulus and renal tubule (Figure 1E).

\section{DISCUSSION}

ACV-induced nephrotoxicity is a serious adverse effect, which can affect treatment outcomes (28). Studies have reported various forms of nephrotoxicity caused by ACV including crystal nephropathy, acute interstitial nephritis, acute tubular necrosis and obstructive nephropathy $(12,29)$. Therapeutic outcomes and patients well-being can be significantly improved by curtailing the nephrotoxic menace of ACV. CUM has shown therapeutic activities against some animal models of diseases (30). This study assessed the protective effect of CUM on ACV-induced nephrotoxicity in rats. The current study supplemented the rats with CUM prior to the induction of nephrotoxicity with ACV. All evaluated renal markers were normal in the CUM-treated rats. On the other hand, ACV had a negative impact on the kidneys of the treated rats by elevating serum creatinine, urea, and uric acid levels. Similarly, Lu et al. (31) reported elevated levels of the aforementioned renal biochemical markers in ACV-treated mice. The kidney accounts for about $60 \%-90 \%$ of ACV elimination. ACV is relatively insoluble in urine; it is filtered by glomeruli and secreted by renal tubules (32). Therefore, ACV crystals can be deposited in renal tubules leading to the obstruction of nephron causing increased resistance to renal blood flow and the elevation of serum creatinine, urea, and uric acid levels $(31,32)$. ACV might have also reduced glomerular filtration rate (GFR) through the induction of renal oxidative stress leading to increased serum creatinine, urea, and uric acid levels. Oxidative stress can induce vasoactive mediators, which can cause renal vasoconstriction or decreased glomerular filtration capacity (33). However, CUM supplementation restored serum creatinine, urea, and uric acid levels in a dose-related fashion. Similarly, Haung et al. (34) reported restored serum renal markers in cyclosporine-induced renal dysfunction in rats supplemented with CUM. In the current study, CUM might have restored the aforementioned renal markers by inhibiting ACV-induced renal obstruction, and oxidative stress, thereby increasing GFR.

The ACV-treated rats showed decreases in serum electrolytes (sodium, potassium, chloride and bicarbonate), total protein and albumin levels. Some studies have also documented electrolytes and protein abnormalities associated with ACV-administration (35). The observation in the current study can be ascribed to ACV-induced increased urinary excretion of the aforementioned parameters. However, serum electrolytes, total protein and albumin levels were stabilized by CUM supplementation in a dose-related fashion. In accordance with this finding, 

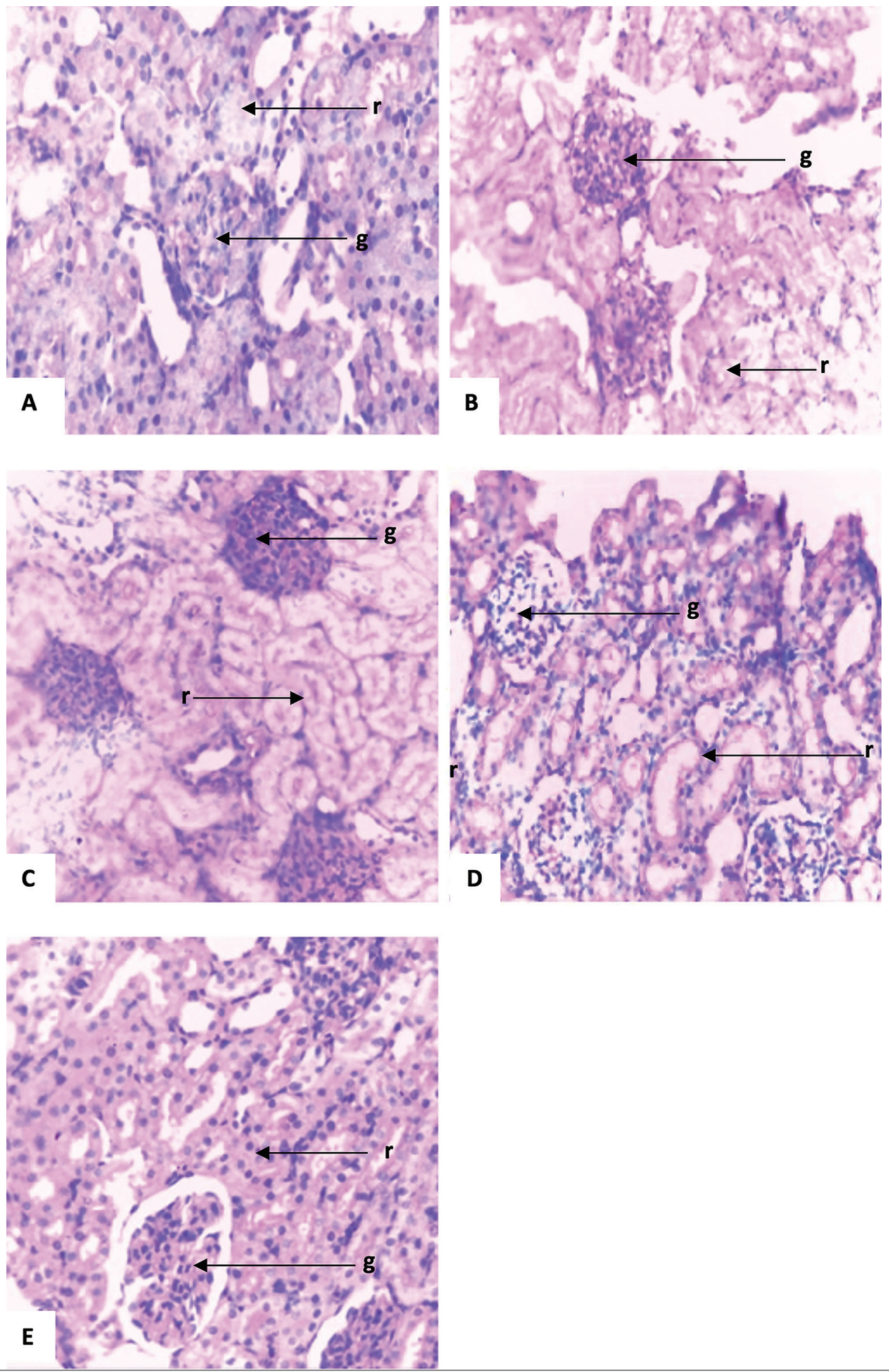

Figure 1. Kidney histology of control (A), ACV-treated (B), ACV+CUM (25 mg/kg)-treated (C), ACV+CUM (50 mg/kg)-treated (D) and $\mathrm{ACV}+\mathrm{CUM}(100 \mathrm{mg} / \mathrm{kg})$-treated (E) rats. Control rats showed normal glomerulus and renal tubule (A), while ACV-treated rats were characterized by hypercellular glomerulus with mesangial proliferation and tubular necrosis (B). CUM (25 and $50 \mathrm{mg} / \mathrm{kg}$ ) administrations to ACV-treated rats resulted in hypercellular glomerulus with mesangial proliferation and normal renal tubule (C and D). CUM (100mg/kg) supplementations led to normal glomerulus and renal tubule structure in ACV-treated rats. g: glomerulus; r: renal tubule. Hematoxylin-Eosin, $x 400$. 
some scholars reported that CUM supplementation improved serum electrolytes and protein levels in a rat model of adriamycin-induced renal dysfunction (36). In the current study, CUM might have stabilized serum electrolytes, total protein and albumin levels by decreasing renal wastage.

ACV also had a negative impact on kidney redox status by decreasing kidney antioxidants (SOD, CAT, GSH and GPx) and increasing MDA concentrations. ACV might have decreased kidney antioxidant concentrations via the induction of oxidative stress as a consequence of ROS generation. The generated ROS might have depleted kidney antioxidants and caused the oxidation of renal lipids (polyunsaturated fatty acid), thereby increasing MDA level (34). Lu et al. (31) also suggested that oxidative damage may be an essential index for ACV-induced renal dysfunction. In the current study, antioxidants were increased whereas MDA levels were decreased in a dose-related fashion in CUM supplemented rats. This finding may be due to the inhibitory impact of CUM on ACV-induced renal oxidative stress by scavenging ROS. This might have increased kidney antioxidant activity, thus facilitating ROS incapacitation by antioxidants and decreased kidney MDA levels.

More so, the alteration in kidney morphology of ACV-treated rats was characterized by hypercellular glomerulus with mesangial proliferation and tubular necrosis. The observations in ACV-treated rats have been previously documented $(37,22)$. The observed changes in the kidney morphology of ACV-treated rats may be a consequence of oxidative stress-induced kidney biomolecular damage (38). Oxidative stress causes lipid peroxidation (LPO). LPO is a process by which free radicals attack lipids especially polyunsaturated fatty acids causing alterations in the physical properties of cellular membranes leading to covalent modifications of proteins and nucleic acids stimulating cytotoxicity, cell necrosis and apoptosis (39). In this study, kidney morphology was restored by CUM supplementation. This observation correlates with Tirkey et al. (40) who reported the ability of CUM to restore kidney morphology in cyclosporine-induced renal dysfunction in rats. Palipoch, et al. (41) also reported improved kidney histology caused by CUM supplementation against cisplatin-induced nephrotoxicity in rats. In the present study, the restored kidney morphology caused by CUM supplementation might be due to the inhibition of ACV-induced kidney oxidative stress, thus arresting kidney LPO and preventing structural and functional damage of kidney biomolecules. CUM might have offered renal protection as a chain-breaking antioxidant, which scavenges and eliminates free radicals such as singlet oxygen, hydroxyl radical, superoxide radicals and peroxyl radicals, which are inducers of oxidative stress (42-44). The inhibitory action of CUM on hydroxyl radical and peroxyl radicals might have prevented kidney proteins and nucleic acids modifications, which might have occurred due to LPO. CUM might have prevented ACV-induced kidney oxidative stress by inhibiting free radical-generating enzymes. Studies have associated CUM with inhibitory action on free radical-generating enzymes such as lipoxygenase/cyclooxygenase and xanthine hydrogenase/ox- idase $(45,46)$. CUM might have also offered renal protection by inhibiting ACV-induced renal inflammation. Studies showed that CUM can reduce inflammation by inhibiting the activities of pro-inflammatory mediators including leukotrienes and cytokines (47).

\section{CONCLUSION}

Based on the findings in the current study, CUM supplementation abrogates ACV-induced nephrotoxicity in a dose-related fashion. It may have clinical application for ACV-associated nephrotoxicity.

\section{Peer-review: Externally peer-reviewed.}

Conflict of Interest: The authors declare that they have no conflicts of interest to disclose.

Financial Disclosure: The authors declare that they have no financial disclosure.

Author Contributions: Conception/Design of study: E.A., J.K.; Data Acquisition: E.A., J.K.; Data Analysis/Interpretation: E.A., J.K.; Drafting Manuscript: E.A., J.K.; Critical Revision of Manuscript: E.A., J.K.; Final Approval and Accountability: E.A., J.K.

Acknowledgement: We appreciate Mr Cosmos Obi of the Pharmacology Laboratory, Department of Pharmacology/ Toxicology, Faculty of Pharmacy, Niger Delta University, Bayelsa State, Nigeria.

\section{REFERENCES}

1. Klahr S. Nonexcretory Functions of the Kidney. In: Klahr S. (eds) The Kidney and Body Fluids in Health and Disease. Springer, Boston, MA, 1983.

2. Arunvikram K, Mohanty I, Sardar KK, Palai S, Sahoo G, Patra RC. Adverse drug reaction and toxicity caused by commonly used antimicrobials in canine practice. Vet World 2014; 7(5): 299-5.

3. Mehta RL, Pascual MT, Soroko S, Savage BR, Himmelfarb J, Ikizler TA, et al. Spectrum of acute renal failure in the intensive care unit: The PICARD experience. Kidney Int 2004; 66: 1613-21.

4. Uchino S, Kellum JA, Bellomo R, Doig GS, Morimatsu H, Morgera $S$, et al. Acute renal failure in critically ill patients: A multinational, multicenter study. JAMA 2005; 294: 813-8.

5. Bryson YJ, Dillon M, Lovett M, Acuna G, Taylor S, Cherry JD, et al. Treatment of first episodes of genital herpes simplex virus infection with oral acyclovir. A randomized double-blind controlled trial in normal subjects. N Engl J Med 1983; 308(16): 916-21.

6. Keeney RE, Kirk LE, Bridgen D. Acyclovir tolerance in humans. Am J Med 1982; 73: 176-81.

7. Chou JW, Yong C, Wootton SH. Case 2: Rash, fever and headache first, do no harm. Paediatr Child Heal 2008; 13: 49-2.

8. Genc G, Ozkaya O, Acikgoz Y, Yapici O, Bek K, GulnarSensoy S, et al. Acute renal failure with acyclovir treatment in a child with leukemia. Drug ChemToxicol 2010; 33: 217-19.

9. Bean B, Aeppli D. Adverse effects of high-dose intravenous acyclovir in ambulatory patients with acute herpes zoster. J Infect Dis 1985; 151: 362-5.

10. Ahmad T, Simmonds M, Mclver AG, McGraw ME. Reversible renal failure in renal transplant patients receiving oral acyclovir prophylaxis. PediatrNephrol 1994; 8: 489-91. 
11. Vomiero G, Carpenter B, Robb I, Filler G. Combination of ceftriaxone and acyclovir an underestimated nephrotoxic potential? Pediatr Nephrol 2002; 17: 633-7.

12. Lu H, Han Y-J, Xu J-D, Xing W-M, Chen J. Proteomic Characterization of Acyclovir-Induced Nephrotoxicity in a Mouse Model. PLoS One 2014; 9(7): 1-6.

13. Aggarwal BB, Kumar A, Bharti AC. Anticancer potential of curcumin: Preclinical and clinical studies. Anticancer Res 2003; 23: 363-98.

14. Gounder DK, Lingmallu J. Comparison of chemical composition and antioxidant potential of volatile oil from fresh dried and cured turmeric (Curcuma longa) rhizomes. Ind Crops and Prod 2012; 38: 124-31.

15. Gupta SC, Patchva S, Aggarwal BB. Therapeutic roles of curcumin: Lessons learned from clinical trials. AAPS J 2013; 15: 195-218.

16. Hewlings SJ, Kalman DS. Curcumin: A review of its' effects on human health. Foods 2017; 6(92): 1-11.

17. Aggarwal BB, Harikumar KB. Potential therapeutic effects of curcumin, the anti-inflammatory agent, against neurodegenerative, cardiovascular, pulmonary, metabolic, autoimmune and neoplastic diseases. Int J Biochem Cell Biol 2009; 41: 40-59.

18. El Shemy MA. Protective effects of curcumin against Augmentin-induced hepatotoxicity in rats. Benha Vet MedJ 2018; 35: 375-86.

19. He L, Peng X, Zhu J, Liu G, Chen X, Tang C, et al. Protective effects of curcumin on acute gentamicininduced nephrotoxicity in rats. Can J PhysiolPharmacol 2015; 93(4): 275-82.

20. Miriyala S, Panchatcharam M, Rengarajulu P. Cardioprotective effects of curcumin. AdvExpMed Biol 2007; 595: 359-77.

21. Chakraborty M, Bhattacharjee A, Kamath JV. Cardioprotective effect of curcumin and piperine combination against cyclophosphamide-induced cardiotoxicity. Indian J Pharmacol 2017; 49(1): 65-70.

22. Campos SB, Seguro AC, Cesar KR, Rocha AS. Effects of acyclovir on renal function. Nephron 1992; 62: 74-9.

23. Buege JA, Aust SD. Microsomal lipid peroxidation. Meth Enzymol 1978; 52: 302-10.

24. Aebi $\mathrm{H}$ Catalase in vitro. In Method in Enzymology, Colowick SP and Kaplane NO, Eds., New York, NY, USA: Academic Press, 1984.

25. Sun M, Zigman S. An improved spectrophotometer assay of superoxide dismutase based on epinephrine, antioxidation. Anal Biochem 1978; 90: 81-9.

26. Sedlak J, Lindsay RH. Estimation of total, protein-bound and non-protein sulfhydryl groups in tissue with Ellman's reagent. Anal Biochem 1968; 25: 192-205.

27. Rotruck JT, Rope AL, Ganther HF, Swason AB. Selenium: biochemical role as a component of glutathione peroxidase. Sci 1973; 179: 588-90.

28. Izzedine $\mathrm{H}$, Launay-Vacher $\mathrm{V}$, Deray $\mathrm{G}$. Antiviral drug-induced nephrotoxicity. Am J Kidney Dis 2005; 45: 804-17.

29. Tucker WE Jr, Macklin AW, Szot RJ, Johnston RE, Elion GB, de Miranda $\mathrm{P}$, et al. Preclinical toxicology studies with acyclovir: Acute and subchronic tests. Fund ApplToxicol 1983; 3: 573-8.
30. Agrawal S, Goel RK. Curcumin and its protective and therapeutic uses. Natl J Physiol PharmPharmacol 2016; 6: 1-8.

31. Lu H, Han YJ, Xu JD, Xing WM, Chen J. Proteomic characterization of acyclovir-induced nephrotoxicity in a mouse model. PLoS One 2014; 9 (7): 1-9.

32. Perazella MA, Crystal-induced acute renal failure. Am J Med 1999; 106(4): 459-65.

33. Damiano S, Andretta E, Longobardi C, Prisco F, Paciello O, Squillacioti $C$, et al. Effects of curcumin on the renal toxicity induced by ochratoxin a in rats. Antioxid 2020; 9(332): 1-13.

34. Huang J, Yao X, Weng G, Qi H and Ye X. Protective effect of curcumin against cyclosporine A-induced rat nephrotoxicity. Mol Med Rep 2018; 17: 6038-44.

35. Chávez-Iñiguez JS, Medina-Gonzalez R, Aguilar-Parra, L. Torres-Vázquez EJ, Maggiani-Aguilera $P$, Cervantes-Pérez E et al. Oral acyclovir induced hypokalemia and acute tubular necrosis a case report. BMC Nephrol 2018; 19(324): 1-5.

36. Venkatesan N, Punithavathi $D$, Arumugam V. Curcumin prevents Adriamycin nephrotoxicity in rats. Br J Pharmacol 2000;129: 231-4.

37. Whitley RJ, Middlebrooks M, Gnann JW, Jr. Acyclovir: The past ten years. Adv Exp Med Biol 1990; 278: 243-53.

38. Dennis JM, Witting PK. Protective role for antioxidants in acute kidney disease. Nutr 2017; 9(7): 718.

39. Gaschler MM, Stockwell BR. Lipid peroxidation in cell death. BiochemBiophys Res Commun 2017; 15(482): 419-25.

40. Tirkey N, Kaur G, Vij G, Chopra K. Curcumin, a diferuloylmethane, attenuates cyclosporine-induced renal dysfunction and oxidative stress in rat kidneys. BMC Pharmacol 2005; 5(15): 1-10.

41. Palipoch S, Punsawad C, Chinnapun D, Suwannalert P. Amelioration of cisplatin-induced nephrotoxicity in rats by curcumin and a-tocopherol. Trop J Pharm Res 2013; 12: 973-9.

42. Yadav VR, Suresh S, Devi K, Yadav S. Effect of cyclodextrin complexation of curcumin on its solubility and antiangiogenic and anti-inflammatory activity in rat colitis model APPS Pharm Sci Tech 2009; 10: 752-62.

43. Maheshwari RK, Singh AK. Multiple biological activities of curcumin: a short review LifeSci 2006; 78: 2081-7.

44. Priyadarsini KI, Maity DK, Naik, GH, Kumar MS, Unnikrishnan MK, Satav JG, et al. Role of phenolic O-H and methylene hydrogen on the free radical reactions and antioxidant activity of curcumin. Free RadicBiol Med 2003; 35: 475-84.

45. Lin YG, Kunnumakkara AB, Nair A, Merritt WM, Han LY, Armaiz-Pena GN, et al. Curcumin inhibits tumor growth and angiogenesis in ovarian carcinoma by targeting the nuclear factor-kB pathway. Clin Cancer Res 2007; 13: 3423-30.

46. Marchiani A, Rozzo C, Fadda A, Delogu G, Ruzza P. Curcumin and curcumin-like molecules: From spice to drugs. Curr Med Chem 2014; 21: 204-22.

47. Kohli K, Ali J, Ansari MJ, Raheman Z. Curcumin: A natural anti-inflammatory agent. Indian J Pharmacol 2005; 37: 141-7. 